I stopped and examined it. Instead of being a flower, I found it was the web of a spider, and it was hanving between the branches of a shrub about three feet from the ground.

The outer lines of the web were of considerable strength and were stretched between points from eight to ten inches apart. From these lines, supported by a few radii, hung a beautiful rosette-shaped centre, much resembling a delicate pattern in white silk lace. The central space was open and measured about a quarter of an inch in diameter. The notched space was adorned by three circular zig-zag cords of thick white flossy silk. I dirl not notice any of MacCook's so-called "ribbon braces." 'The spiral space was very open and the threads composing it were so slight as to be almost invisible. So thin were they that the ribboned centre appeared to be hanging in the air without any support whatever. The appearance of this web was almost exactly similar to that of the web of Uloborus, shown in Fig. 57, p. 58 of MacCook's "American Spiders." I did not notice any "fenders" or protective wings on the outer side of the web; there were, however, a few strengthening strantls on the side turned towards the bush.

The web, however, especially bore a strong resemblance to a flower, the more so as in the exact centre of its outward side was stationed a spider with a light blue body. This light blue colour gave one the impression that it was the centre of the flower, while the yellow legs spotted with brown were symmetrically disposed in the shape of an $X$ across the ribboned hub, thus dividing it into the semblance of petals. The illusion was remarkable.

The spider remained motionless until I touched the web. She then fell into the net which I was holding under the snare.

As soon as she touched the net (a white gauze one) she changed colour. From blue she became white and then, on being shaken, her body turned a dark greenish brown. I then placed her in a glass tube and gradually she resumed her blue tint. Whenever shaken, however, she turned a greenish brown. I placed her in spirits and her colour remained a grey brown.

On the same road later in the day, I noticed another strange web which bore even a stronger resemblanec to a flower.

The "foundation space" was the same as in the other, but somewhat larger and stronger. The white silk ribbon, however, instead of being disposed around the centre in circular zig.zag lines, was extended in two thick white ribbons stretched cros, wise along four of the radii. In this instance also the spiral space was very open and the spirals very delicate.

The spider inhabiting this web was considerably larger than the foregoing specimen, but appeared to be otherwise exactly similar to it. Her body was a very light blue, placed exactly in the centre of the cro,s, hcad downwards, while her long legs were disposed in pairs over the four arms of the white silk pattern. The whole thing bore a great resemblance to an orchid, and the legs of the spider gave it just sufficient stability for it to be taken ior a flower.

When I touched the web the spider immediately darted through two strands in the spiral space and placed herself on the reverse side of her web, being alurost completely concealed by the thick flossy white ribbons.

I eaptured this spider, and her body, like the other specimen's, immediately turned a dark greenish brown. I did not, however, see her turn white. I placed the insect in a glass tube, and five days later put her in a cage.

I also took the web and succeeded in fastening the centre of it on to a black card, where it remains in exactly the same shape as when it was hanging on the bushes. I have this web, and also a photograph of it.

The day alter the spider was placed in the cage she made a web. It was spun during the night, and I did not observe the operation. The web was of the same pattern as the one on which I discovered her on the bush. It did not have any circular zig-zag cords.

This spider remained in her cage for four or five weeks, and then I placed her in spirits. She was fed principally with flies.

On one occasion I put a very large blue-bottle fly into the cage. The spider seized it imuediately, violently vibrated her web, and at the same time rolled the fly round and round betw'een her legs. In the space of three or four seconds the fly was completely swathed in an envelope of white silk, and was motionless. The spider then fastened her fang; into the body, and sucked it for about two hours.

I have since seen several of these spiders on their webs, and have noticed that the pattern of the snare appears to depend on

NO. 1224 , VOL. 47] the size of the insect, the smaller specimens making the circular rosette-shaped snare, while the larger insects weave the cross orchid-like flower. I saw one small web composed of two little rosettes, joined side by side, but $l$ did not notice whether it was inhabited by two spiders. I frequently found wings and other debris of insects hanging to the rosettes of the webs, and in one case saw a wing of what must have been a butterfly of considerable size.

When does the spider alter the pattern of her snare? Can it be that, when the spider attains to full growth, finding that the rosette shape, becoming too large, no longer deceives butterflies and other insects, she adopts the orchid-like pattern which has more zraisemblance, and over which she can clispose her long legs with a better chance of successful trickery.

The web of this spider being so like a flower would appear to be intended as a veritable "suare." The insect by assuming its bright blue colour increase: the resemblance and the mimicry is probably practised not so much for the protection of the spider herself, but rather for the attraction it presents to butterfies and other flower frequenting insects.

MacCook in "American Spiders," writing of the mimicry of spiders, and of their perception of colour, says (vol, ii. p. 346) :"There is indeed another theory which may be suggested, namely, that the colour surrounclings of the spider, in some manner not now explicable, so rapidly influence the organism of the creature that a change of colour is produced in harmony with its environment. Can zee suppose in this case that the spider possesses the power to influence at will the chromatophores or pig. ment bodies, so that she may change her colour with changing site?"

The specimen observed by me would seem to be an answer to MacCook's suggestion, and I should be very glad to know, through the medium of NATURE, or otherwise, whether the spider described by me, as above, is already known 10 naturalists.

I took the specimens which I possess to the Natural History Museum, at South Kensington, and the spiders were declared to be a species of Argiope.

\section{H. H. J. BeII,}

Senior Assistant Treasurer, Gold Coast Colony.

20, Sussex Villas, Keisington, W

\section{Origin of Lake Basins.}

ONE of the chief rcasons for the prevalence of lake basin; in glaciated countries has $n, t$ been alluded to in the letters which have recently appeared in NATURE on the origin of lake basins.

Whenever earth movements take place in limited areas such movements will tend to form basius, but as the movements are as a rule gradual such basins will only come into existence under exceptional conditions. Water-borne detritus, the growth of vegetation, and erosion will obliterate them in most cases as fast as they are formed by slow unequal movements of subsidence or elevation.

In glaciated countries, however, basins in the course of forma tion by unequal earth movements will be largely protected from such destructive action by being filled with ice, and will thus be preserved to appear as lake basins when the ice melts.

So, too, in countries where the rainfall is very small and the action of the forces destructive to lake basins is accordingly much diminished basins may be and are formed by earth movements. In rainless countries they are probably more numerous than we are aware of, for there is little to attract attention to them, but they will become of more importance as works of irrigation are required in such countries. An im. portant depression, the Raiän basin, has lately been surveyed in Egypt by Mr. Cope Whitehouse with a view to utilising it fur irrigation purposes (Proceeding Royal Geographical Society, and series, vol. ix. p. 608).

Wind-borne detritus will tend to diminish the depths of such basins in rainless countries. So, too, the capacity of ice-lilled basins to huld water in the future will be diminished somewhat by the erosion of the sub-glacial river, but on the other hand as the movement of the earth deepens the basin the ever-thickening mass of ice will acquire increased power to grind it deeper still. This grinding action cannot be ignored, and some shallow lake basins may be almost entirely due to it, but there is scarcely a limit to the formation of such basins by earth movements under suilable conditions.

J. C. HAWKSHAW

33, Great George Street, Westminster, S.W., March 29. 